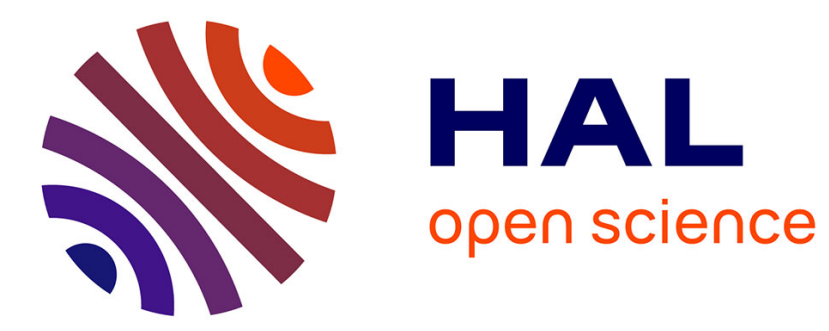

\title{
Is it possible to assess the allergenicity of mixtures based on in chemico methods? Preliminary results on common fragrance aldehydes
}

Matthieu Lang, Elena Gimenéz Arnau, Jean-Pierre Lepoittevin

\section{- To cite this version:}

Matthieu Lang, Elena Gimenéz Arnau, Jean-Pierre Lepoittevin. Is it possible to assess the allergenicity of mixtures based on in chemico methods? Preliminary results on common fragrance aldehydes. Flavour and Fragrance Journal, 2016, 32 (1), pp.63-71. 10.1002/ffj.3359 . hal-02119640

\section{HAL Id: hal-02119640 \\ https://hal.science/hal-02119640}

Submitted on 3 May 2019

HAL is a multi-disciplinary open access archive for the deposit and dissemination of scientific research documents, whether they are published or not. The documents may come from teaching and research institutions in France or abroad, or from public or private research centers.
L'archive ouverte pluridisciplinaire HAL, est destinée au dépôt et à la diffusion de documents scientifiques de niveau recherche, publiés ou non, émanant des établissements d'enseignement et de recherche français ou étrangers, des laboratoires publics ou privés. 


\section{Is it possible to assess the allergenicity of mixtures based on in chemico methods? Preliminary results on common fragrance aldehydes}

Matthieu Lang, Elena Giménez-Arnau* and Jean-Pierre Lepoittevin*

Laboratoire de Dermatochimie, Institut de Chimie de Strasbourg (CNRS UMR 7177), Université de Strasbourg, Institut le Bel, 4 Rue Blaise Pascal, 67081 Strasbourg, France

* Correspondence to:

Elena Giménez-Arnau/Jean-Pierre Lepoittevin

Laboratoire de Dermatochimie

Institut le Bel

4 Rue Blaise Pascal, 67081 Strasbourg, France

Tel: +33368851525

Fax: +33 368851527

e-mail: egimenez@unistra.fr; jplepoit@unistra.fr

There are no conflicts of interests

Short Title: Skin sensitization of fragrance aldehyde mixtures? 


\begin{abstract}
Most perfume compositions and cosmetics contain mixtures of fragrance ingredients, synthetic or extracted from natural sources. Many of these are known to be weak or moderate allergens when tested individually. However, fragrances are one of the most common causes of allergic contact dermatitis to consumer products, ranking second after nickel. As consumers are exposed to mixtures of ingredients when using products that contain perfume, it was suggested that mixtures could enhance induction and elicitation of skin allergy to fragrances. Prediction of skin sensitization to chemicals is crucial for the cosmetics industry. Nowadays, methods to assess skin sensitization hazard replacing the use of animals have been developed and validated for the testing of pure substances. However, there is practically no experience with testing of mixtures. Here we evaluated in a very preliminary approach, and from a chemical reactivity perspective, if the validated DPRA, hapten-peptide reactivity based assay, could be used at a first sight to evaluate the chemical reactivity of mixtures. Two simple binary combinations of fragrance aldehydes were studied, hydroxycitronellal-citral and citral-cinnamaldehyde. Their reactivity towards DPRA peptides was compared with that of the single constituents. In general, the chemical described as the most potent sensitizer was driving the reactivity in the mixtures. Therefore, it could be hypothesised that the DPRA would estimate the mixture chemical reactivity similar to that of the stronger sensitizer component. This will be reinforced by conditions described for the DPRA where the tested chemical or mixture of chemicals will be added in large excess to the peptides.
\end{abstract}

\title{
Keywords
}

Fragrance aldehydes; mixtures; allergenicity; hapten-peptide reactivity 


\section{Introduction}

Approximately 3000 fragrance ingredients, of synthetic or natural origin, are currently available to the perfumer for compounding a fragrance formula." Thus, a single perfume or fragrance composition may consist of 10-300 different ingredients. Many of these are known to be weak or for some of them moderate skin sensitizers when tested individually. ${ }^{[2,31}$ However, in most dermatological centres fragrances rank second after nickel as the most common source of contact allergy. The main tools for diagnosing allergic contact dermatitis (ACD) to fragrances are Fragrance Mix I (amyl cinnamal, cinnamal, cinnamyl alcohol, eugenol, isoeugenol, geraniol, hydroxycitronellal, oak moss) and Fragrance Mix II (hydroxyisohexyl-3-cyclohexene carboxaldehyde, citral, farnesol, coumarin, citronellol, $\alpha$-hexyl cinnamal), both included in the European base-line patch test series..$^{[4.5]}$ A response rate of $6-11 \%$ to Fragrance Mix I, and of 2.1-4.6\% to Fragrance Mix II has been reported in dermatological patients suffering from ACD..$^{[6,7]}$

As most perfumes contain mixtures of fragrance ingredients, and many of them have a skinsensitizing capacity, consumers are almost certainly exposed to mixtures of allergens, also called cocktails, when they use products that contain perfume. Very often, at least one of the 26 individual fragrance ingredients identified as sensitizers that need to be labelled on the packaging of cosmetic products according to EU regulations (Annex 3 Cosmetics Directive 76/768/EEC) is present in consumer products. It might be thus possible that the existence of several fragrance compounds together in a consumer product could lead to increased sensitization potency.Recently, we investigated if there is any influence when mixing fragrance allergens on the sensitization process to the individual compounds ${ }^{[81}$ Mice were sensitized with three different concentrations of three fragrance compounds, hydroxyisohexyl 3-cyclohexene carboxaldehyde, isoeugenol and cinnamaldehyde, alone or as a mixture. The sensitization and elicitation responses were measured by ear thickness plus infiltration of $\mathrm{B}$ and $\mathrm{T}$ cells, and $\mathrm{T}$ cell proliferation in the draining lymph nodes. Results showed a dose-dependent sensitization response for each compound and an increased response when they were mixed. A stronger challenge response to cinnamaldehyde was observed in mice sensitized with the mixture than in mice sensitized with cinnamaldehyde alone. We conducted similar studies with atranol and chloroatranol, main allergens of oak moss absolute, showing that the mixture in the natural extract was more potent at both sensitization and challenge than atranol and chloroatranol alone. ${ }^{(91}$ These findings suggested that allergen mixtures could enhance both induction and elicitation of ACD.

Assessment of the skin sensitizing potential of chemicals is crucial for the cosmetics industry. Following the adoption of REACH, ${ }^{\text {,10 }}$ but even more with the 7 th amendment to the EU Cosmetics Directive banning from the European market cosmetic products containing ingredients tested on animals, ${ }^{[! \prime}$ a great deal of progress has been made in the development of alternative methods to animal tests to assess skin sensitization to chemicals. ${ }^{122}$ However, a major drawback of these methods is their inability to assess the sensitizing potential of mixtures or cocktails of chemicals. 
A key step in the sensitization process to any compound is the formation of a covalent adduct by its reaction with skin proteins, generally through a nucleophile-electrophile mechanism, forming this way an immunogenic complex. ${ }^{[13]}$ The formation of the hapten-protein complex, able to be fully recognized by naïve $\mathrm{T}$ cells, is one of the mandatory conditions for skin allergy to occur. In chemico alternative tests, such as the Direct Peptide Reactivity Assay (DPRA), are based on this capacity of chemical sensitizers to react with amino acids. To develop the DPRA, Gerberick et al. evaluated 82 chemicals, including allergens of different potencies and non-allergenic chemicals, for their ability to react with glutathione and two synthetic peptides having cysteine (Cys) or lysine (Lys) as the reactive amino acid ( $N$-Ac-Arg-Phe-Ala-Ala-X-Ala-Ala; Pep-Cys if $\mathrm{X}=\mathrm{Cys}$; Pep-Lys if $\mathrm{X}=\mathrm{Lys}$ ), and measured peptide depletion using UV detection. ${ }^{[1]}$ Peptide reactivity data were compared with existing in vivo local lymph node assay (LLNA) data using recursive partitioning methodology. In general, moderate, strong and extreme sensitizers showed moderate to high peptide reactivity, while weak and non-sensitizers showed minimal to low reactivity. A classification tree model was then built based on a Pep-Cys and Pep-Lys depletion pattern. Classifying minimal reactivity as non-sensitizers and low, moderate and high reactivity as sensitizers, it was determined that the model based on cysteine and lysine gave a prediction accuracy of $89 \% .{ }^{1151}$ The DPRA was first endorsed by the European centre for validation of alternative methods (ECVAM) ${ }^{1 !\rceil}$ and was recently adopted as an OECD-guideline for the testing of chemicals under section 4-health effects. ${ }^{[1]}$

As most toxicological methods, the DPRA was developed for the evaluation of the skin sensitizing potential of chemicals when taken individually. For many years we conducted studies in order to validate the peptide reactivity assay concept, and to complement depletion data observed for those chemicals. ${ }^{118203}$ However, the behaviour of the DPRA to evaluate the reactivity of chemical mixtures is not known. In the work detailed herein we studied the reactivity of binary mixtures of fragrance sensitizers towards DPRA peptides, and we compared this reactivity with that of the constituents alone. The aim was to perform mechanistic based studies in order to evaluate, in a very first approach, if the reactivity towards DPRA peptides of allergens in a mixture was modified compared to the one of the single compounds, and if this was significant enough to help for the prediction of skin sensitization. Compounds tested were fragrance aldehydes hydroxycitronellal $\mathbf{1}$, citral $\mathbf{2}$ and cinnamaldehyde $\mathbf{3}$ (Figure 1). 


\section{Materials and Methods}

\section{Chemistry}

Hydroxycitronellal ${ }^{13} \mathrm{C}$-substituted at position 1 , 1-( $\left.{ }^{13} \mathbf{C}\right)-\mathbf{1}$, and citral ${ }^{13} \mathrm{C}$-substituted at positions 1 , 1$\left.{ }^{13} \mathbf{C}\right)-2$, and 3, 3-(13 $\left.\mathbf{C}\right)-2$, were synthesized using a procedure we reported previously ${ }^{1181}$ Synthesis of cinnamaldehyde ${ }^{13} \mathrm{C}$-substituted at positions $1, \mathbf{1 -}\left({ }^{13} \mathbf{C}\right)-\mathbf{3}$, and $3, \mathbf{3 -}\left({ }^{13} \mathbf{C}\right)-\mathbf{3}$ is reported herein. 1$\left({ }^{1} \mathrm{C}\right)$ Acetonitrile, 1-( $\left.{ }^{13} \mathrm{C}\right)$ benzaldehyde and deuterated solvents were purchased from Euriso-Top (Saint Aubin, France). All other chemicals were purchased from Sigma-Aldrich (Saint Quentin Fallavier, France). Chemicals and solvents were used as delivered. Air- or moisture-sensitive reactions were conducted in flame-dried glassware under an atmosphere of dry argon. Reactions were followed by thin layer chromatography on $0.25 \mathrm{~mm}$ silica gel plates $\left(60 \mathrm{~F}_{254}\right.$; Merck, Darmstadt, Germany). After migration, the plates were inspected under UV light $(254 \mathrm{~nm})$ or sprayed with a solution containing phosphomolybdic acid (5 g), cerium (IV) sulfate $(2 \mathrm{~g})$ and sulphuric acid (12 $\mathrm{mL})$ in water (188 $\mathrm{mL})$, followed by heating. Column chromatography purifications were performed on silica gel 60 (Merck, Geduran $\left.{ }^{\circledR}, 40-63 \mu \mathrm{m}\right) .{ }^{1} \mathrm{H}$ and ${ }^{13} \mathrm{C}$ NMR spectra were recorded on a Bruker Avance 300 spectrometer at $300 \mathrm{MHz}$ and $75 \mathrm{MHz}$, respectively. The chemical shifts $(\delta)$ are reported in ppm and are indirectly referenced to TMS via the solvent signal $\left(\mathrm{CDCl}_{3}: \delta{ }^{1} \mathrm{H}=7.26, \delta^{13} \mathrm{C}=77.16\right)$. In the ${ }^{1} \mathrm{H}$ NMR spectra multiplicities are denoted as $\mathrm{d}$ (doublet) and $\mathrm{m}$ (multiplet). The different types of carbon in the structures were identified by the DEPT-135 technique.

1-( $\left.{ }^{13} \mathbf{C}\right)$ Cinnamaldehyde, 1-( $\left.{ }^{13} \mathbf{C}\right)-3$. To a solution of freshly distilled diisopropylamine (1.06 $\mathrm{mL}, 7.52$ mmol, 4 equiv) in dry tetrahydrofuran $(6 \mathrm{~mL})$ was slowly added a solution of $n$-butyllithium $(1.64 \mathrm{M}$ in hexane, $4.59 \mathrm{~mL}, 7.52 \mathrm{mmol}, 4$ equiv) at $-20^{\circ} \mathrm{C}$. The reaction medium was stirred for $30 \mathrm{~min}$ at $-20^{\circ} \mathrm{C}$, then cooled down to $-70^{\circ} \mathrm{C}$. A solution of $1-\left({ }^{3} \mathrm{C}\right)$ acetonitrile $(197 \mu \mathrm{L}, 3.76 \mathrm{mmol}, 2$ equiv) in dry tetrahydrofuran $(3 \mathrm{~mL})$ was then added. After $30 \mathrm{~min}$, the reaction medium was allowed to warm up to $0^{\circ} \mathrm{C}$, and a solution of diethylchlorophosphate $(575 \mu \mathrm{L}, 3.76 \mathrm{mmol}, 2$ equiv) in dry tetrahydrofuran $(3$ $\mathrm{mL}$ ) was added slowly. After $1 \mathrm{~h}$ of stirring at $0^{\circ} \mathrm{C}$, a solution of freshly distilled benzaldehyde (192 $\mu \mathrm{L}, 1.88 \mathrm{mmol})$ in dry tetrahydrofuran $(3 \mathrm{~mL})$ was added. The mixture was kept under stirring at room temperature for an additional $3 \mathrm{~h}$ and then hydrolysed with water $(30 \mathrm{~mL})$. The aqueous layer was extracted with diethyl ether $(3 \times 30 \mathrm{~mL})$ and the combined organic layers washed with brine $(50 \mathrm{~mL})$, dried over $\mathrm{MgSO}_{4}$, filtered and concentrated under reduced pressure. The crude oil was directly used without purification for the next step.

To a solution of the previously obtained crude oil in dry dichloromethane $(20 \mathrm{~mL})$, was slowly added a solution of diisobutylaluminium hydride (1 $\mathrm{M}$ in hexane, $7.52 \mathrm{~mL}, 7.52 \mathrm{mmol}, 4$ equiv) at $78^{\circ} \mathrm{C}$ drop by drop. After 15 min stirring at $-78^{\circ} \mathrm{C}$, the reaction medium was allowed to warm up to room temperature and then stirred for an additional $2 \mathrm{~h}$. The reaction mixture was hydrolysed with tartrate buffer $(45 \mathrm{~mL})$ and kept under stirring for $12 \mathrm{~h}$. The aqueous layer was extracted with 
dichloromethane $(4 \times 20 \mathrm{~mL})$ and combined organic layers washed with brine $(60 \mathrm{~mL})$, dried over $\mathrm{MgSO}_{4}$, filtered, and concentrated under reduced pressure. The crude oil was purified by distillation under reduced pressure $\left(90^{\circ} \mathrm{C}\right.$ at 4 mbar) to give 1-( $\left.{ }^{13} \mathbf{C}\right)-3(177 \mathrm{mg}, 1.34 \mathrm{mmol}, 71 \%$ yield $)$ as a yellow oil. Only the $E$ isomer was observed by NMR. ${ }^{H} \mathrm{NMR}\left(300 \mathrm{MHz}, \mathrm{CDCl}_{3}\right): \delta 6.68\left(\mathrm{ddd}, 1 \mathrm{H},{ }^{3} \mathrm{Hн}_{\mathrm{Hн}}=15.8\right.$ $\left.\mathrm{Hz},{ }^{3} \boldsymbol{J}_{\text {нн }}=7.5 \mathrm{~Hz},{ }^{2} \boldsymbol{J}_{\text {нс }}=1.2 \mathrm{~Hz},-\mathrm{CH}^{\mathrm{s}} \mathrm{CHO}\right), 7.40\left(\mathrm{~d}, 1 \mathrm{H},{ }^{3} \boldsymbol{J}_{\text {нн }}=15.8 \mathrm{~Hz},-\mathrm{CHCH}{ }^{1 \mathrm{l}} \mathrm{CHO}\right), 7.39-7.49(\mathrm{~m}, 3 \mathrm{H}, 2$ $\times m-\mathrm{CH}(\mathrm{Ar}), p-\mathrm{CH}(\mathrm{Ar})), 7.51-7.55(\mathrm{~m}, 2 \mathrm{H}, 2 \times o-\mathrm{CH}(\mathrm{Ar})), 9.67\left(\mathrm{dd}, 1 \mathrm{H},{ }^{\prime} J_{\mathrm{Hс}}=172.0 \mathrm{~Hz},{ }^{3} J_{\mathrm{нн}}=7.5 \mathrm{~Hz},-\right.$ $\left.{ }^{\mathrm{a}} \mathrm{CHO}\right) .{ }^{\mathrm{r}} \mathrm{C} \mathrm{NMR}\left(75 \mathrm{MHz}, \mathrm{CDCl}_{3}\right): \delta 128.6\left(\mathrm{~d},{ }^{\prime} \mathrm{J}_{\mathrm{cc}}=55.4 \mathrm{~Hz},-\mathrm{CH}^{\mathrm{s}} \mathrm{CHO}\right), 128.5(2 \times o-C H(\mathrm{Ar})), 129.1$ $(2 \times m-C H(A r)), 131.3(p-C H(A r)), 134.0(-C(\mathrm{Ar})), 152.8\left(\mathrm{~d},{ }^{2} J_{c c}=4.3 \mathrm{~Hz},-C \mathrm{HCH}^{13} \mathrm{CHO}\right), 193.7(-$ $\left.{ }^{13} \mathrm{CHO}\right)$.

3-( $\left.{ }^{13} \mathbf{C}\right)$ Cinnamaldehyde, 3-( $\left.{ }^{13} \mathbf{C}\right)-3$. Same methodology used for the synthesis of 1-( $\left.{ }^{13} \mathrm{C}\right)$ cinnamaldehyde but with the following reagents: $2.56 \mathrm{~mL}$ freshly distilled diisopropylamine (18.3 mmol, 4 equiv), 30 $\mathrm{mL}$ dry tetrahydrofuran, $11.40 \mathrm{~mL} n$-butyllithium (1.60 $\mathrm{M}$ in hexane, $18.3 \mathrm{mmol}, 4$ equiv), $478 \mu \mathrm{L}$ dry acetonitrile (9.15 mmol, 2 equiv), $1.40 \mathrm{~mL}$ diethylchlorophosphate (9.15 mmol, 2 equiv), $479 \mu \mathrm{L} \mathrm{1-}$ ( $\left.{ }^{13} \mathrm{C}\right)$ benzaldehyde $(98 \%, 4.57 \mathrm{mmol}), 50 \mathrm{~mL}$ dry dichloromethane, $18.3 \mathrm{~mL}$ diisobutylaluminium hydride ( $1 \mathrm{M}$ in hexane, $18.4 \mathrm{mmol}, 4$ equiv) and $112 \mathrm{~mL}$ tartrate buffer. The crude oil was purified by distillation under reduced pressure $\left(90^{\circ} \mathrm{C}\right.$ at 4 mbar) to give $\mathbf{3 -}\left({ }^{13} \mathbf{C}\right)-3$ (265 $\mathrm{mg}, 1.99 \mathrm{mmol}, 44 \%$ yield) as a yellow oil $(E / Z>98 \%)$. $\mathrm{H}$ NMR $\left(300 \mathrm{MHz}, \mathrm{CDCl}_{3}\right): \delta 6.69\left(\mathrm{dd}, 1 \mathrm{H},{ }^{3} J_{\text {нн }}=15.9 \mathrm{~Hz},{ }^{3} \boldsymbol{H н}_{\text {нн}}=7.7 \mathrm{~Hz},-\right.$ $\mathrm{CHCHO}), 7.42-7.45(\mathrm{~m}, 3 \mathrm{H}, 2 \times m-\mathrm{CH}(\mathrm{Ar}), p-\mathrm{CH}(\mathrm{Ar})), 7.55-7.60$ (m, 2H, $2 \times o-\mathrm{CH}(\mathrm{Ar})), 7.60(\mathrm{dd}$, $\left.1 \mathrm{H},{ }^{\prime} J_{\text {нс }}=152.2 \mathrm{~Hz},{ }^{3} J_{\text {нн }}=16.3 \mathrm{~Hz},{ }^{13} \mathrm{CHCHCHO}\right), 9.72\left(\mathrm{dd}, 1 \mathrm{H},{ }^{3} J_{\text {нн }}=7.7 \mathrm{~Hz},{ }^{3} J_{\text {нс }}=0.9 \mathrm{~Hz},-\mathrm{CHO}\right) .{ }^{13} \mathrm{C} \mathrm{NMR}$ $\left(75 \mathrm{MHz} \mathrm{CDCl}_{3}\right): E$ isomer, $\delta 128.6\left(\mathrm{~d}, \mathrm{~J}_{\mathrm{cc}}=68.5 \mathrm{~Hz},-C \mathrm{HCHO}\right), 128.6(2 \times m-C \mathrm{H}(\mathrm{Ar})), 129.1(2 \times o-$ $C H(\mathrm{Ar})), 131.3(p-C H(\mathrm{Ar})), 134.2\left(\mathrm{~d},{ }^{\prime} J_{\mathrm{cc}}=55.8 \mathrm{~Hz},-C(\mathrm{Ar})\right), 152.8\left({ }^{13} \mathrm{CHCHCHO}\right), 193.7\left(\mathrm{~d},{ }^{2} \mathrm{~J}_{\mathrm{cc}}=4.7\right.$ $\mathrm{Hz},-\mathrm{CHO})$.

\section{Peptides for Reactivity Studies}

Synthetic peptides Pep-Cys and Pep-Lys were furnished by Genepep SA (Prades le Lez, France) and purity $(>95 \%)$ was certified by HPLC.

\section{Reaction of Aldehydes with Pep-Cys}

For the reaction of each single aldehyde with Pep-Cys, the chemical (6 $4 \mathrm{~mol})$ was dissolved in a mixture of deuterated acetonitrile $(200 \mu \mathrm{L})$ and phosphate buffer $\mathrm{pH} 7.4(400 \mu \mathrm{L})$. Then Pep-Cys $(6$ $\mu \mathrm{mol}, 1$ equiv) was added to the medium and the whole mixture introduced into a NMR tube to follow the reaction by ${ }^{13} \mathrm{C}$ NMR. For the reaction of binary mixtures, the two chemicals (6 $\mu \mathrm{mol}$ each) were dissolved in a mixture of deuterated acetonitrile $(200 \mu \mathrm{L})$ and phosphate buffer pH $7.4(400 \mu \mathrm{L})$. PepCys ( $6 \mu \mathrm{mol}, 1$ equiv) was added to the medium and the whole mixture introduced into a NMR tube to follow the reaction by ${ }^{13} \mathrm{C}$ NMR. Kinetic studies were carried out with the same experimental conditions 
adding tert-butanol $(10 \mu \mathrm{L})$ as internal standard for the calculation of the relative intensities of ${ }^{{ }^{3} \mathrm{C}}$ NMR peaks.

\section{Reaction of Aldehydes with Pep-Lys}

For the reaction of each single aldehyde with Pep-Lys, the chemical (6 $\mu \mathrm{mol})$ was dissolved in a mixture of deuterated acetonitrile $(200 \mu \mathrm{L})$ and ammonium acetate buffer $\mathrm{pH} 10.2$ (400 $\mu \mathrm{L})$. Then PepLys (6 $\mu$ mol, 1 equiv) was added to the medium and the whole mixture introduced into a NMR tube to follow the reaction by ${ }^{13} \mathrm{C}$ NMR. For the reaction of binary mixtures, the two chemicals (6 $\mu$ mol each) were dissolved in a mixture of deuterated acetonitrile (200 $\mu \mathrm{L})$ and ammonium acetate buffer $\mathrm{pH} 10.2$ (400 $\mu \mathrm{L})$. Pep-Lys (6 $\mu$ mol, 1 equiv) was added to the medium and the whole mixture introduced into a NMR tube to follow the reaction by ${ }^{13} \mathrm{C}$ NMR. Kinetic studies were carried out with the same experimental conditions adding tert-butanol $(10 \mu \mathrm{L})$ as internal standard for the calculation of the relative intensities of ${ }^{13} \mathrm{C}$ NMR peaks.

\section{NMR Experiments and Structure Assignment}

The reactions were followed by mono-dimensional ${ }^{\mathrm{B}} \mathrm{C}$ NMR on a Bruker Avance 300 spectrometer at $75 \mathrm{MHz}$. Chemical shifts $(\delta)$ are reported in ppm in comparison to TMS, using the residual signal of acetonitrile $\left({ }^{\mathrm{H}} \mathrm{H}, \delta=21.94 \mathrm{ppm} ;{ }^{\mathrm{B}} \mathrm{C}, \delta=118.26 \mathrm{ppm}\right)$ as internal standard. ${ }^{\mathrm{i}} \mathrm{C}$ peak integrations were calculated using the signal of tert-butanol $(\delta=29.23 \mathrm{ppm})$ or deuterated tert-butanol $(\delta=68.46 \mathrm{ppm})$ as internal standard with NMRTEC/NMR notebook software (version 2.0, NMRtec ${ }^{\circledR}$, IllkirchGraffenstaden, France). The structure of the products formed during the reactions was assigned by heteronuclear single-quantum correlation (HSQC) and heteronuclear multiple-bond correlation (HMBC) experiments, and by combining all information from the different " $\mathrm{C}$-substituted positions. Bi-dimensional ${ }^{\prime} \mathrm{H}-{ }^{13} \mathrm{C}$ heteronuclear experiments were carried out on a Bruker Avance 400 spectrometer $\left(\mathrm{H}, 400 \mathrm{MHz}\right.$; $\left.{ }^{3} \mathrm{C}, 100 \mathrm{MHz}\right)$. Chemical shifts $(\delta)$ were compared with those calculated using ACD/CNMR and ACD/HNMR Predictor software (version 6.0, ACD/Labs, Toronto, Canada). 


\section{Results and Discussion}

Fragrance aldehydes chosen for the study were hydroxycitronellal 1, citral $\mathbf{2}$ and cinnamaldehyde $\mathbf{3}$ (Figure 1). Hydroxycitronellal and cinnamaldehyde are constituents of Fragrance Mix I, and citral is included in Fragrance Mix II. The three of them belong to the 26 fragrance ingredients list (Annex 3 Cosmetics Directive 76/768/EEC) identifying sensitizers that need to be labelled on the packaging of cosmetic products. Hydroxycitronellal and citral are classified as weak sensitizers according to the LLNA, ${ }^{121}{ }^{221}$ but are of important clinical relevance due to the high exposure of consumers. Cinnamaldehyde is classified as a moderate sensitizer up to the LLNA, ${ }^{[1,221}$ but for long time it was considered as a top-ranking fragrance allergen, ${ }^{132.24}$ though a decline in reactions has been seen from the beginning of the 2000s. ${ }^{[31}$ We used two binary mixtures of these aldehydes. A mixture hydroxycitronellal-citral was chosen to represent two weak sensitizers together, and a mixture citralcinnamaldehyde to exemplify a pair weak-moderate sensitizers, according to LLNA data.

The use of ${ }^{13} \mathrm{C}$-substituted molecules in association with NMR techniques is a powerful tool we have developed for the investigation of hapten-protein interactions. ${ }^{\text {peras }}$ Best results are obtained using direct substitution at the reactive sites of the molecule. Thus, hydroxycitronellal was prepared "C substituted at the reactive electrophilic aldehyde chemical function (1-("C)-1). Citral and cinnamaldehyde were prepared "C substituted at the aldehyde chemical function position 1 (1-("C)-2,

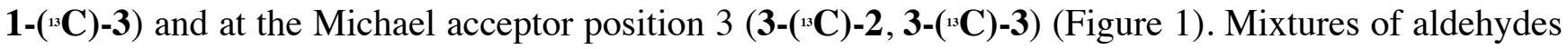
were then reacted with 1 equivalent of the nucleophilic peptides Pep-Cys and Pep-Lys.

\section{Binary Mixture Hydroxycitronellal-Citral}

The behaviour towards Pep-Cys and Pep-Lys was studied using two binary mixtures, 1-(" $\mathbf{C})-\mathbf{1} / \mathbf{1}-\left({ }^{\mathrm{B}} \mathbf{C}\right)-\mathbf{2}$ and 1-( $\left.{ }^{(\mathrm{C}} \mathbf{C}\right)-\mathbf{1} / \mathbf{3}-\left({ }^{(} \mathbf{C}\right)-2$. Reactions were followed by mono-dimensional "C NMR, and the chemical structure of the products formed was elucidated by using a combination of bi-dimensional $\mathrm{H}$ and $\mathrm{B}$ data obtained from all "C substituted positions.

\section{Reaction of hydroxycitronellal and citral towards Pep-Cys}

We first studied the reactivity of hydroxycitronellal and citral separately with Pep-Cys in order to determine structures of potential adducts formed and their NMR $\delta$ characteristics. The adducts characterized were in accordance with those we had observed in previous studies. ${ }^{18,2,29}$ We used these data to elucidate the structure of adducts formed when hydroxycitronellal and citral were in an equimolar mixture.

Figure 2 is representative of the chemistry observed in the reaction of the mixture hydroxycitronellal-citral with the thiol chemical group from Pep-Cys. Results were analogous with both mixtures 1-( $\left.{ }^{\mathrm{B}} \mathbf{C}\right)-\mathbf{1} / \mathbf{1}-\left({ }^{\mathrm{B}} \mathbf{C}\right)-\mathbf{2}$ and $\mathbf{1 -}\left({ }^{\mathrm{C}} \mathbf{C}\right)-\mathbf{1} / \mathbf{3}-\left({ }^{\mathrm{B}} \mathbf{C}\right)-\mathbf{2}$. When starting the reaction (day 0) the signal of the hydrated form of hydroxycitronellal 4 at 89.4 ppm was observed and only citral reacted with the thiol group of Cys on the Michael position. The $\delta$ at $46.7 \mathrm{ppm}$ indicated the formation of adduct 5 already at the first day of the reaction. The spectra were strictly the same one-month later, showing no 
more evolution of the reaction. This was also the reactivity observed for citral when treated alone with Pep-Cys. Contrariwise, hydroxycitronellal was found reactive when treated separately with Pep-Cys affording classical adducts derived from addition of the thiol group of Cys on the carbonyl chemical function.

Reaction of hydroxycitronellal and citral towards Pep-Lys

According to the DPRA protocol, the $\mathrm{pH}$ of the Pep-Lys reaction was set at 10.2 (ammonium acetate buffer solution) in order to increase the reactivity of the amino group of the lateral chain of $\mathrm{Lys}_{\mathrm{s}}\left(\mathrm{p} K_{\mathrm{a}}\right.$ $10.43 \pm 0.1)$. Results were strictly the same with both mixtures $\mathbf{1 -}\left({ }^{13} \mathbf{C}\right)-\mathbf{1} / \mathbf{1}-\left({ }^{13} \mathbf{C}\right)-\mathbf{2}$ and $\mathbf{1 -}\left({ }^{13} \mathbf{C}\right)-\mathbf{1} / \mathbf{3}-\left({ }^{13} \mathbf{C}\right)-$ 2. Adducts characterized are shown in Figure 3. Their characteristic $\delta$ were compared with those of adducts formed by reaction of each constituent alone with Pep-Lys. Hydroxycitronellal and citral formed the same adducts separately with Pep-Lys or when mixed. At the first day of the reaction, the hydrated form 4 of hydroxycitronellal was formed together with adduct $\mathbf{6}$, resulting from a nucleophilic attack of the amino group of Lys on the carbonyl function, followed by displacement of a water molecule to form imine 7. Also, through a similar mechanism, citral reacted with the amino group of Lys to form a Schiff base, together with addition of a water molecule on position 3, affording this way adducts 8-10. After 8 days of reaction, citral was completely consumed in the mixture.

\section{Kinetic competition results}

The percentage over time of hydroxycitronellal and citral in the binary mixtures in the presence of the peptides is shown in Figure 4. In the reaction with Pep-Cys hydroxycitronellal was found essentially non-reacting compared to citral that was more reactive. The mixture behaved basically as if citral was the only reagent present. In other words, hydroxycitronellal reacted with Pep-Cys individually but seemed to be non reactive in presence of citral. Looking at the loss of citral in the mixture over time, only around $20 \%$ was consumed after 25 days (Figure 4). If reactivity was directly related to adduct formation with Pep-Cys, theoretically $80 \%$ of Pep-Cys would still be available for reaction with hydroxycitronellal. However it has been reported that several fragrance aldehydes included citral are able to oxidise Pep-Cys and other test peptides containing Lys and Cys residues by some unknown mechanisms. ${ }^{[301}$ Ideally, a quantitative analysis of unreacted Pep-Cys should indicate if the peptide was still present in the mixture in the parent form and thus available for reaction or if it did oxidize. Reactivity with Pep-Lys showed a complete disappearance of citral after 8 days of reaction, the reaction being faster than with Pep-Cys, and a low consumption of hydroxycitronellal. Citral reacted preferentially with Pep-Lys, with only 50\% still present in the mixture after $24 \mathrm{~h}$ of reaction.

\section{Discussion of the results}

Hydroxycitronellal and citral are both categorized as weak sensitizers in the LLNA with average $\mathrm{EC}_{3}$ (\%) values of 20 and 13, respectively. Recently, based on human data, hydroxycitronellal has indeed been classified as an infrequent cause of contact allergy in relation to level of exposure. However, citral has been classified as a common cause of contact allergy but with a substantial degree of exposure necessary. ${ }^{\left[{ }^{31}\right.}$ Based on clinical data citral seems therefore to have a higher relative skin sensitizing 
potency. This is also supported by DPRA results, hydroxycitronellal being classified as a low reactivity chemical with Pep-Cys and Pep-Lys depletions of $17.5 \%$ and $6.5 \%$ respectively, whereas citral was classified as a moderate reactivity chemical with depletion values of $85.7 \%$ and $16.9 \%$, respectively. Consistent with these data, in our reactivity studies the mixture behaved basically as if citral, which could be considered as a stronger sensitizer than hydroxycitronellal, was the unique reagent present, and thus the main sensitizer in the mixture. It could then be concluded that the reactivity of the mixture is similar to that of the stronger sensitizer constituent that is also the most reactive. Thus it could be expected that the DPRA would predict this mixture to have a moderate chemical reactivity. For a sensitizer to be classified as having a moderate chemical reactivity in the DPRA it needs to deplete Pep-Cys $>22.6 \%$ and Pep-Lys $\leq 42.5 \%$, being depletion directly correlated with reactivity (Figure 5). However, in the binary mixture citral had a higher reactivity with Pep-Lys than with Pep-Cys (Figure 4) but experimental conditions were not the same as DPRA. In our approach, equimolar mixtures were used for the studies in order to assess the possible competition between the two allergens towards the peptides, whereas in the DPRA there is a peptide to chemical ratio of 1:10 for Pep-Cys and 1:50 for Pep-Lys. Also, even if adducts were formed, reactivity of the aldehydes could result in other processes too, such as degradation of the molecule itself or oxidation of the peptide catalysed by the test compound as mentioned earlier. ${ }^{[301}$ The DPRA would most probably consider the mixture as having a weak sensitizing activity.

\section{Binary Mixture Citral-Cinnamaldehyde}

The behaviour towards Pep-Cys and Pep-Lys was studied using two binary mixtures, 1-( $\left.{ }^{13} \mathbf{C}\right)-\mathbf{2} / \mathbf{1}-\left({ }^{13} \mathbf{C}\right)-\mathbf{3}$ and 3-( $\left.{ }^{13} \mathbf{C}\right)-2 / 3-\left({ }^{13} \mathbf{C}\right)-3$. Reactions were followed by mono-dimensional ${ }^{13} \mathrm{C} N \mathrm{NR}$. A combination of bidimensional $\mathrm{H}$ and ${ }^{1 \mathrm{C}}$ data obtained from all ${ }^{13} \mathrm{C}$ substituted positions was used to elucidate the chemical structure of the products formed.

\section{Reaction of citral and cinnamaldehyde towards Pep-Cys}

We previously studied the reactivity of citral and cinnamaldehyde separately with Pep-Cys in order to determine structures of potential adducts formed and their NMR $\delta$ characteristics. We used these data to elucidate the structure of adducts formed when studying the citral-cinnamaldehyde mixture.

Figure 6 is representative of the chemistry observed when the mixture citral-cinnamaldehyde was reacted with the thiol chemical group from Pep-Cys. Results were identical with the two binary mixtures used. Clearly, adducts were formed by Michael addition of the thiol group of Pep-Cys on the conjugated double bond of cinnamaldehyde. No reaction with citral was observed. The signal with $\delta$ at $41.9 \mathrm{ppm}$ for the $\mathrm{C}-3$ position corresponded well with compound 11. This signal was in agreement with the one observed at $202.7 \mathrm{ppm}$ in the reactions with ${ }^{13} \mathrm{C}-1$ substitution and characteristic of an aldehyde chemical function (spectra not shown). Compound $\mathbf{1 1}$ was in equilibrium in the reaction media with the corresponding hydrated form. $\delta$ at about $44.7 \mathrm{ppm}$ for C-3 and at 88.2 for C-1 were indeed distinctive 
of 12. Same adducts 11-12 were identified in the individual reaction of cinnamaldehyde with the peptide. Thus, at first sight, cinnamaldehyde was much more reactive than citral.

Adducts 11 and 12 appeared at the very beginning of the reaction (day 0, one hour) and disappeared completely with time. These results probably suggested that cinnamaldehyde formed, very fast, unstable adducts with Pep-Cys that could afterwards dissociate to furnish both precursors. It is known that an equilibrium can be established between $\alpha, \beta$-unsaturated aldehydes and their Cys adducts. Previous studies showed that half-lives of the adducts and kinetics of the reverse reactions varied widely depending on the nature of the adduct and on the carbonyl structure studied. ${ }^{321}$ The reaction of Pep-Cys with conjugated carbonyls treated here is thus most probably a chemical equilibrium between adducts and the precursors. Further investigation is needed to confirm this hypothesis. The equilibrium constants as well as the rate constants for the reverse reactions, depending on the experimental conditions used and on the chemical structure of the aldehyde, should be determined, this not being the purpose of our investigation here.

\section{Reaction of citral and cinnamaldehyde towards Pep-Lys}

Results were similar with both mixtures 1-( $\left.{ }^{13} \mathbf{C}\right)-\mathbf{2} / \mathbf{1}-\left({ }^{13} \mathbf{C}\right)-3$ and $\mathbf{3 -}\left({ }^{13} \mathbf{C}\right)-\mathbf{2} / \mathbf{3}-\left({ }^{13} \mathbf{C}\right)-3$. Adducts characterized are shown in Figure 7. Their characteristic $\delta$ were compared with those of adducts formed by reaction of each constituent alone with Pep-Lys.

At the very beginning of the reaction only citral 8 adduct (Figure 3), resulting from Schiff base formation with the amino group of Lys, was observed with $\delta$ at $160.5 \mathrm{ppm}$ in the experiments with ${ }^{13} \mathrm{C}-1$ substitution and at $152.7 \mathrm{ppm}$ with ${ }^{13} \mathrm{C}-3$ substitution. Over time, these signals disappeared in benefit of further hydrated derivatives as the 10-like adduct at $62.5 \mathrm{ppm}\left({ }^{13} \mathrm{C}-1\right)$ and $50.9 \mathrm{ppm}\left({ }^{13} \mathrm{C}-3\right)$ and of the new observed adduct 13 with characteristic $\delta$ at $66.4 \mathrm{ppm}\left({ }^{\left.1{ }^{1} \mathrm{C}-1\right)}\right)$ and $123.5 \mathrm{ppm}\left({ }^{1 \mathrm{C}} \mathrm{C}-3\right)$. Figure 7 shows the mono-dimensional ${ }^{13} \mathrm{C}$ NMR spectrum of the reaction $\left.\mathbf{1 - (}{ }^{13} \mathbf{C}\right)-\mathbf{2} / \mathbf{1 -}\left({ }^{13} \mathbf{C}\right)-3 /$ Pep-Lys at day 20 , where all identified adducts were formed. No more evolution was seen, with citral and cinnamaldehyde practically consumed. Besides citral adducts, a comparable reactivity was observed for cinnamaldehyde with identification of adducts 14-16 (Figure 7), previously characterized when tested individually on Pep-Lys. The Schiff base 14 with characteristic $\delta$ at $164.2 \mathrm{ppm}\left({ }^{\mathrm{B}} \mathrm{C}-1\right)$ and $142.6 \mathrm{ppm}\left({ }^{\mathrm{C}} \mathrm{C}-3\right)$ was formed through the reaction of the carbonyl group with the amino residue of lysine, together with intermediary and hydrolysis products $\mathbf{1 5}$ and $\mathbf{1 6}$.

\section{Kinetic competition results}

The percentage over time of citral and cinnamaldehyde in the binary mixtures in the presence of the peptides is reported in Figure 8. When following the reactivity with Pep-Cys every 30 min during two days, we saw that cinnamaldehyde reacted much faster than citral during the first $24 \mathrm{~h}$. But when tracing the curves of the reaction over 37 days, the concentration of cinnamaldehyde significantly increased, certainly due to the reversed equilibrium evoked in the previous section between cinnamaldehyde and its Pep-Cys adducts. No significant decrease in the concentration of citral was 
noticed during the first $24 \mathrm{~h}$ of the reaction. At first sight and comparing with cinnamaldehyde it could be argued that the presence of the methyl group in the Michael position of citral could disadvantage the addition of the thiol group of Pep-Cys on this position. However, reaction of Pep-Cys on the Michael position of citral was observed when tested alone after several days of reaction (data not shown). It is interesting to note that we observed a very slow decrease in the citral concentration in the mixture over time (till 37 days). This was in agreement with spectra in Figure 6 that showed a weakening of the characteristic signal of 3-( $\left.{ }^{13} \mathbf{C}\right)-2$ at $168 \mathrm{ppm}$ at day 36 . Even if we were unable to distinguish any new signal corresponding to a potential adduct, one could thus hypothesise that adducts formed between citral and Pep-Cys seem to be thermodynamically more stable than those formed with cinnamaldehyde. Only around 35\% cinnamaldehyde was consumed (Figure 8), and theoretically around 65\% of Pep-Cys would still be available for reaction. As it was discussed for the mixture hydroxycitronellal-citral, PepCys could have been chemically modified (i. e. oxidised) during the mixture experiment becoming then non reactive..$^{1301}$ However, analysis of what became the unreacted peptide was not in the scope of the study reported herein.

Citral reacted completely after 6 days in presence of Pep-Lys, and cinnamaldehyde reacted gradually during the follow-up of the reaction. But then again, at the very beginning of the reaction, reactivity of cinnamaldehyde was higher than that of citral. The practically complete consumption of both sensitizers with time did not reflect only their reactivity towards Pep-Lys. Indeed, the amount of Pep-Lys available in the mixture was not enough to completely consume citral and cinnamaldehyde (2/3/Pep-Lys in a 1:1:1 ratio). Chemicals were initially stable in the buffer. Something may thus happen in the mixture, aside from peptide reaction, that could produce secondary reactions responsible for their complete consumption. Even if we did not observe it in the NMR studies, one suggestion could be that the use of ammonium acetate buffer, in order to increase the reactivity of the amino group of the lateral chain of lysine, involved the presence in the media of ammonia that could also react with the aldehydes.

\section{Discussion of the results}

All in all, it looked like the reactivity of the mixture was driven by cinnamaldehyde during the initial hours. This was in agreement with known data for both compounds. Cinnamaldehyde has a LLNA average $\mathrm{EC}_{3}(\%)$ value of 2 , being categorized as a stronger sensitizer than citral $\left(\mathrm{EC}_{3} 13 \%\right)$. ${ }^{[3]}$ Also, studies based on clinical data classified cinnamaldehyde as possessing stronger intrinsic sensitizing potency. ${ }^{\mid 311}$ The authors even expected that regular contact with moderate concentrations was likely to sensitize 1 to $10 \%$ of those so exposed. DPRA results with Pep-Cys and Pep-Lys classified cinnamaldehyde as a moderate to strong reactivity chemical with depletion values of $70.6 \%$ and $43.2 \%$ respectively, whereas citral was just a moderate reactivity chemical with depletion values of $85.7 \%$ and $16.9 \%$ (Figure 5). ${ }^{[14]}$ In our studies with Pep-Lys, although cinnamaldehyde showed a strong reactivity at the very beginning of the reaction, citral was more reactive at $24 \mathrm{~h}$ (Figure 8 ) and was the first compound to be completely consumed after seven days (data not shown). All adducts identified resulted from addition of Lys on the aldehyde chemical function of the compounds (Schiff base 
formation). Considering the reaction with Lys there was thus certainly a difference in the kinetics of Schiff base formation between both compounds when mixed. The fact that both sensitizers reacted through a similar chemical mechanism with Pep-Lys indicated probably a synergistic effect. It was thus not possible to reduce the reactivity of this mixture towards Pep-Lys to the behaviour of one single component. Moreover, as stated earlier, something else may happen in the mixture, aside from peptide reaction, that could produce other reactions explaining the complete consumption of both aldehydes in the long term, even if not observed in the NMR spectra.

Looking at the DPRA decisional tree on Figure 5, it could be expected the citral-cinnamaldehyde mixture being predicted having at least a moderate chemical reactivity. Reactivity studies with Pep-Cys showed that the mixture behaved as if cinnamaldehyde was the major reagent present, and thus the main sensitizer in the mixture. Such observations lead us to believe that in the case of testing the mixture with the DPRA, Pep-Cys depletion would be comparable to that of single cinnamaldehyde. However, Pep-Lys reactivity of both aldehydes in the mixture was expressed in an equivalent manner, although not necessarily identical. In a DPRA test, Pep-Lys depletion would result from reactivity of the two molecules in the mixture and thus the prediction would certainly be overestimated. Because of, Pep-Lys depletion of the mixture may exceed $42.5 \%$ and this would classify it as having a strong chemical reactivity. Indeed, Pep-Lys depletion values being $16.9 \%$ for citral and $43.2 \%$ for cinnamaldehyde it could be expected that Pep-Lys depletion by the mixture would be enough to classify it as having a strong reactivity. Still, for consumer protection it is probably best that the DPRA upgrades some mixtures and not the opposite. 


\section{Conclusion}

Several in silico, in vitro, and in chemico alternative methods have been developed this last decade in order to assess skin sensitization to chemicals, following the ban on animal testing introduced by cosmetic legislation in Europe in 2013. Some of these methods, such as the in chemico DPRA, the in vitro ARE-Nrf2 luciferase assay (KeratinoSens ${ }^{\mathrm{rm}}$ ) and the human Cell Line Activation test (h-CLAT), have been recently adopted by the Organization for Economic Cooperation and Development (OECD) for testing health effects of chemicals. ${ }^{17,3,3,34}$ These tests were developed and validated for the testing of pure substances. However, in the cosmetic field, active ingredients are often mixtures from natural sources together with synthetic compounds, and a fragrance formula may consist of 10-300 or more different ingredients in a consumer product. Moreover, REACH regulation requires not only pure substances to be registered, but also registration of mixtures extracted from natural sources. Though, there is very little experience with testing of mixtures, and assessment of test material with more than one component has been proved to be an elusive task in existing methods. The in vivo LLNA was used nevertheless to test a number of essential oils and authors stated that in general the potency of each essential oil did not differ significantly from that of its main individual component. ${ }^{\text {sis }}$ Also, the applicability of the KeratinoSens ${ }^{\mathrm{TM}}$ assay has been evaluated recently as a proof of concept for four plant extracts used in cosmetics, spiked with different doses of citral, cinnamaldehyde and isoeugenol. ${ }^{\text {Bso }}$ The extracts were negative in the test whereas they were positive when spiked with the sensitizers. In this manuscript, we evaluated in a very simple first approach, and from the chemical reactivity point of view, if the DPRA could be used at a first sight to evaluate the reactivity-allergenicity of mixtures. Two simple binary combinations of fragrance aldehydes were chosen, hydroxycitronellal-citral and citralcinnamaldehyde. Qualitative assessment of adduct formation between the aldehydes in the mixtures and Pep-Cys and Pep-Lys was carried out. Further studies on the loss of test chemicals in the mixtures with time were attempted leaving many questions open. The studies showed that aldehydes in the mixtures could react with the peptides, indicating that the DPRA could detect the presence of sensitizers in the mixtures. In general, the most reactive chemical in each mixture was described as the most important sensitizer up to LLNA and DPRA data, which is a positive point. Therefore, it could be hypothesized that the DPRA would estimate the chemical reactivity of the mixture similar to that of the stronger sensitizer component. However, several drawbacks suggested that the DPRA decisional tree could be no longer valid for the evaluation of the studied mixtures. Considering that reactivity of the chemicals towards Pep-Cys and Pep-Lys should be directly correlated to the depletions of the peptides, there were some significant differences in the behaviour of the chemicals when tested individually or in the mixtures. Citral was much more reactive in the mixture than hydroxycitronellal, but it reacted more with Pep-Lys than with Pep-Cys. The depletions of both peptides would then be overexpressed and underestimated respectively. On another hand, even if cinnamaldehyde was more reactive in the mixture than citral with Pep-Cys, both compounds reacted enough with Pep-Lys and thus we could extrapolate that reactivity of the mixture resulted from the sum of both reactivities. Pep-Lys depletion would be then overestimated. In all cases, as we were dealing with aldehydes, the Lys-containing 
peptide facilitated Schiff base formation resulting in greater reactivity. Second to that, attempts to calculate kinetic constants and rates by plugging the logarithm of the concentration of chemicals present in the mixtures against time resulted in bad non-exploitable outcomes. As a conclusion, from a very first sight based on a hapten-peptide reactivity approach, the assessment of the reactivity of mixtures by using the DPRA could be attempted if one component is much more reactive and thus more strongly sensitizing than the other (i. e. strong against weak sensitizers) but becomes difficult when components are of close sensitizing potential such as fragrance aldehydes (weak or moderate) having high Lys reactivity.

Our very first approach studies were based on the hypothetical assumption that loss of chemicals in the mixtures was directly related to peptide reactivity. It cannot be excluded, however, that other processes may influence the reactivity of the test chemicals and thus skew the results. Here, adduct formation and depletion of test chemicals was studied. In the DPRA the opposite is done, depletion of the peptides is analysed. In order to match results observed, further DPRA analysis of the mixtures are thus necessary, at simple routine concentrations and at the ratios used in here. Data on the behaviour of the DPRA peptides in the mixtures would indeed give added value data. Other issues that need to be further evaluated such as DPRA values for the mixtures are LLNA values, equivalents and number of ingredients, dose-response curves, time of reading, kinetic rates and peptide depletions due to redox processes. 


\section{References}

1. International Fragrance Association, www.ifraorg.org.

2. S. C. Rastogi, in Fragrances: beneficial and adverse effects (Eds: P. J. Frosch, J. D. Johansen, I. R. White), Springer-Verlag, Berlin-Heidelberg, 1998, pp. 113-120.

3. J. D. Johansen, J.-P. Lepoittevin, in Contact Dermatitis, $5^{\text {th }}$ edition (Eds: J. D. Johansen, P. J. Frosch, J.-P. Lepoittevin), Springer-Verlag, Berlin-Heidelberg, 2011, pp. 607-627.

4. W. G. Larsen. Arch. Dermatol. 1977, 113, 623.

5. P. J. Frosch, C. Pirker, S. C. Rastogi, K. E. Andersen, M. Bruze, C. Svedman, A. Goossens, I. R. White, W. Uter, E. Giménez-Arnau, J.-P. Lepoittevin, T. Menné, J. D. Johansen. Contact Dermatitis 2005, 52, 207.

6. W. Uter, J. Geier, A. Schnuch, P. J. Frosch. J. Eur. Acad. Dermatol. Venereol. 2007, $21,374$.

7. A. Nardelli, A. Carbonez, W. Ottoy, J. Drieghe, A. Goossens. Contact Dermatitis 2008, 58, 134.

8. C. Menné Bonefeld, M. M. Nielsen, I. M. C. Rubin, M. T. Venegaard, S. Dabelsteen, E. GiménezArnau, J.-P. Lepoittevin, C. Geisler, J. D. Johansen. Contact Dermatitis 2011, 65, 336.

9. C. Menné Bonefeld, M. M. Nielsen, E. Giménez-Arnau, M. Lang, M. T. Venegaard, C. Geisler, J. D. Johansen, J.-P. Lepoittevin. Contact Dermatitis 2014, 70, 282.

10. Anon. (2006) Regulation (EC) No 1907/2006 of the European Parliament and of the Council of the 18 December 2006 concerning the Registration, Evaluation, Authorisation and Restriction of Chemicals (REACH), establishing a European Chemicals Agency. Off. J. Eur. Union L396, 1-849.

11. Anon. (2003) Directive 2003/15/EC of the European Parliament and of the Council of 27 February 2003 amending Council Directive 76/768/EEC on the approximation of the laws of the Member States relating to cosmetic products $-7^{\text {th }}$ Amendment to the European Cosmetics Directive. Off. $J$. Eur. Union L66, 26-35.

12. S. Adler, D. Basketter, S. Creton, O. Pelkonen et al. Arch. Toxicol. 2011, 85, 367.

13. J.-P. Lepoittevin, in Contact Dermatitis, $5^{\text {th }}$ edition (Eds: J. D. Johansen, P. J. Frosch, J.-P. Lepoittevin), Springer-Verlag, Berlin-Heidelberg, 2011, pp. 91-110.

14. G. F. Gerberick, J. D. Vassallo, R. E. Bailey, J. G. Chaney, S. W. Morrall, J.-P. Lepoittevin. Toxicol. Sci. 2004, 81, 332 .

15. G. F. Gerberick, J. D. Vassallo, L. Foertsch, B. Price, J. G. Chaney, J.-P. Lepoittevin. Toxicol. Sci. 2007, 97, 417.

16. Anon. (2013) EURL-ECVAM recommendation on the peptide reactivity assay (DPRA) for skin sensitization testing. https://eurl-ecvam.jrc.ec.europa.eu/eurl-ecvam-recommendations/filesdpra/EURL_ECVAM_Recommendation_DPRA_2013.pdf

17. Anon. (2015) Test No. 442C: In Chemico Skin Sensitisation Direct peptide Reactivity Assay (DPRA). OECD guidelines for the testing of chemicals, DOI: $10.1787 / 20745788$.

18. F. Merckel, G. Bernard, J. Mutschler, E. Giménez-Arnau, G. F. Gerberick, J.-P. Lepoittevin. Chem. Res. Toxicol. 2010, 23, 1433. 
19. J. Mutschler, E. Giménez-Arnau, L. Foertsch, G. F. Gerberick, J.-P. Lepoittevin. Toxicol. in Vitro 2009, 23, 439.

20. F. Merckel, E. Giménez-Arnau, G. F. Gerberick, J.-P. Lepoittevin. Toxicol. Lett. 2013, $218,266$.

21. G. F. Gerberick, C. A. Ryan, P. S. Kern, H. Schlatter, R. J. Dearman, I. Kimber, G. Y. Patlewicz, D. A. Basketter. Dermatitis 2005, 16, 157.

22. D. Basketter, I. Kimber, in Contact Dermatitis, 5" edition (Eds: J. D. Johansen, P. J. Frosch, J.-P. Lepoittevin), Springer-Verlag, Berlin-Heidelberg, 2011, pp. 229-239.

23. F. Enders, B. Przybilla, J. Ring. Contact Dermatitis 1989, 20, 237.

24. A. Schnuch, W. Uter, J. Geier, H. Lessmann, P. J. Frosch. Contact Dermatitis 2007, 57, 1.

25. D. A. Buckley, S. H. Wakelin, D. Holloway, R. J. G. Rycroft, I. R. White, J. P. McFadden. Br. J. Dermatol. 2000, 142, 279.

26. J. Eilstein, E. Giménez-Arnau, D. Duché, F. Rousset, J.-P. Lepoittevin. Chem. Res. Toxicol. 2006, $19,1248$.

27. O. Fleischel, E. Giménez-Arnau, J.-P. Lepoittevin. Chem. Res. Toxicol. 2009, 22, 1106.

28. M. Kireche, E. Giménez-Arnau, J.-P. Lepoittevin. Contact Dermatitis 2010, 63, 192.

29. J. Mutschler. Study of the chemical reactivity of sensitizing molecules towards peptides as part of the development of alternative methods for the detection of allergens. Unpublished doctoral thesis, University of Strasbourg, France, 2007.

30. A. Natsch, H. Gfeller, M. Rothaupt, G. Ellis. Toxicol. in Vitro 2007, 21, 1220.

31. D. Basketter, N. Alépée, T. Ashikaga, J. Barroso, N. Gilmour et al. Dermatitis 2014, 25, 11.

32. H. Esterabauer, A. Ertl, N. Scholz. Tetrahedron 1976, 32, 285.

33. Anon. (2015) Test No. 442D: In Vitro Skin Sensitisation, ARE-Nrf2 Luciferase Test Method, OECD guidelines for the testing of chemicals. DOI: $10.1787 / 9789264229822$.

34. https://www .oecd.org/env/ehs/testing/151216-Draft-h-CLAT-TG-After-Expert-Meeting-(clean)Final.pdf

35. A. M. Api, J. Lalko. Food Chem. Toxicol. 2006, 44, 739.

36. E. Andres, V. M. Sá-Rocha, C. Barrichello, T. Haupt, G. Ellis, A. Natsch. Toxicol. in Vitro, 2013, 27,1220 . 
Figure 1

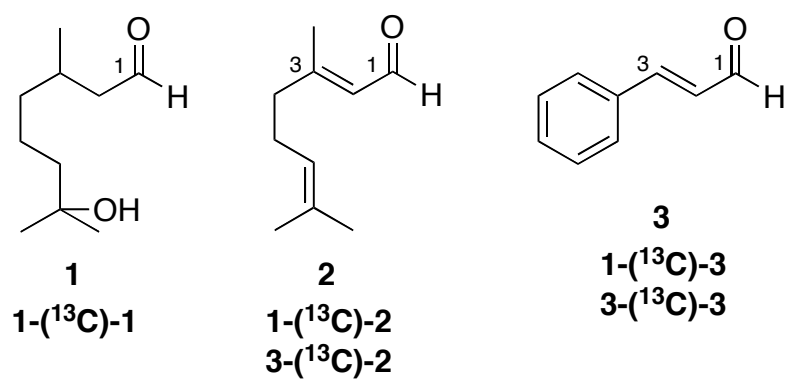

Figure 1. Chemical structures of hydroxycitronellal 1, citral $\mathbf{2}$ and cinnamaldehyde $\mathbf{3}$ 
Figure 2

$1-\left({ }^{13} \mathrm{C}\right)-1 / 3-\left({ }^{13} \mathrm{C}\right)-2 /$ Pep-Cys at day 0
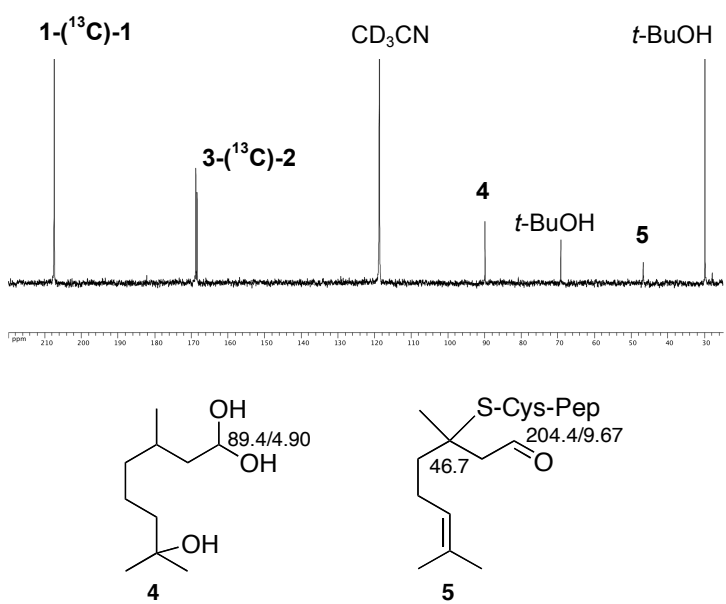

Figure 2. Reactivity hydroxycitronellal-citral with Pep-Cys: representative 1D ${ }^{\mathrm{C}} \mathrm{C}$ NMR spectra and characteristic ${ }^{13} \mathrm{C}$ and ${ }^{~} \mathrm{H}$ data of products formed 
Figure 3

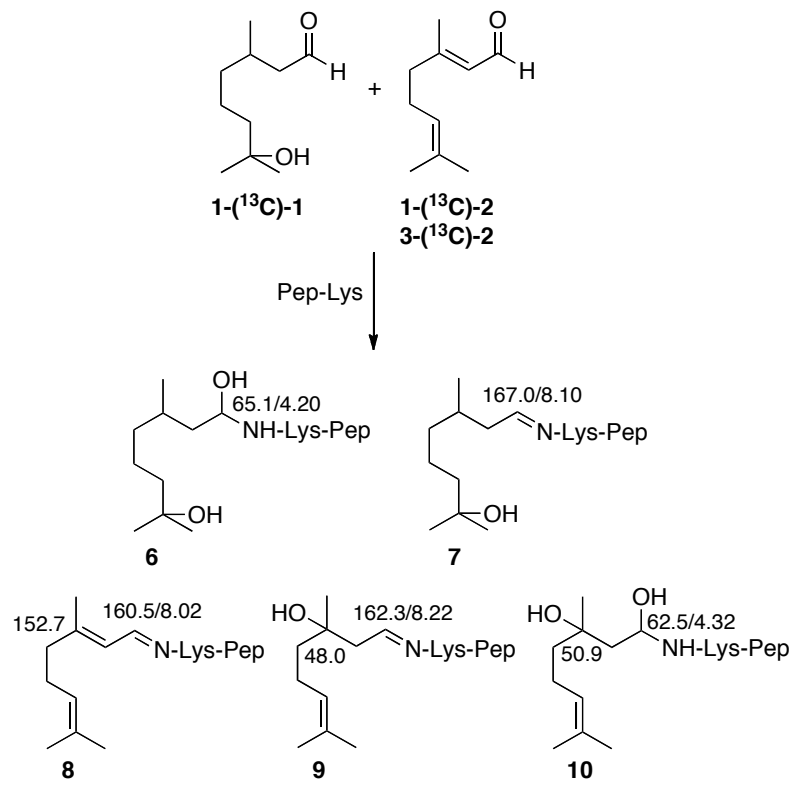

Figure 3. Reactivity hydroxycitronellal-citral/Pep-Lys: adducts formed and characteristic ${ }^{\mathrm{s}} \mathrm{C}$ and ${ }^{\prime} \mathrm{H}$ NMR chemical shifts 
Figure 4

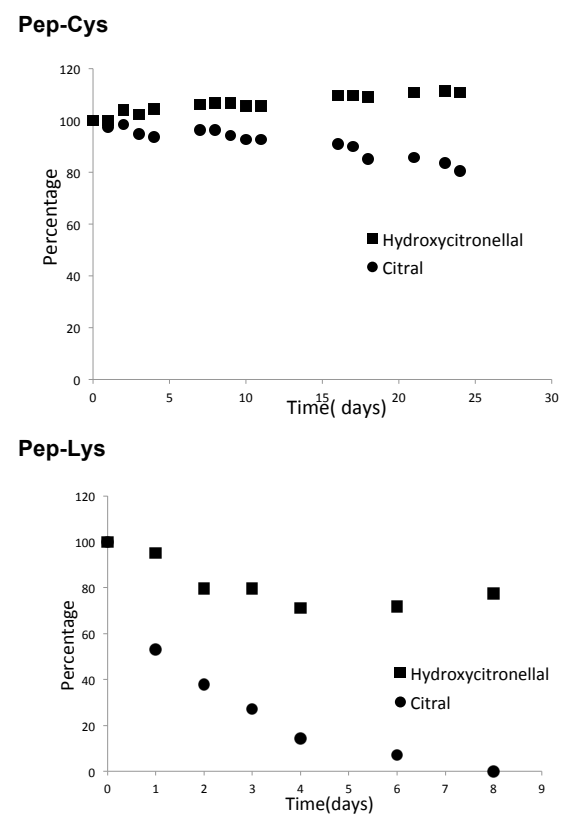

Figure 4. Evolution as a function of time of the concentration of hydroxycitronellal and citral in the mixtures in the presence of Pep-Cys and Pep-Lys 


\section{Figure 5}

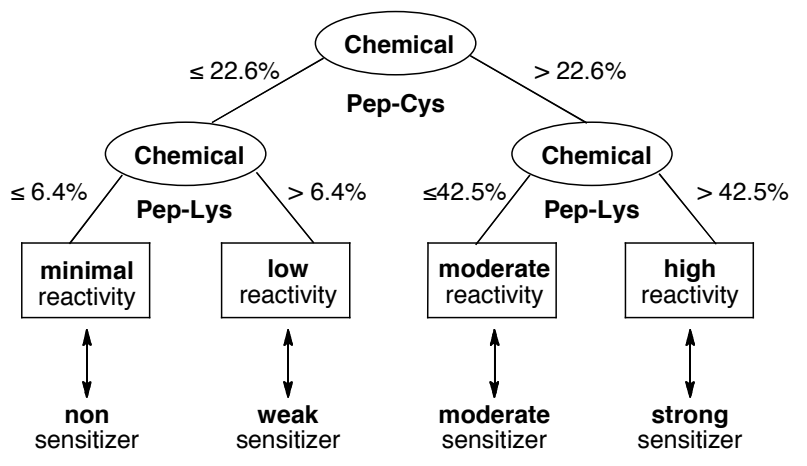

Figure 5. DPRA decisional classification tree, and putative association with sensitization potential classes ${ }^{[15]}$ 
Figure 6

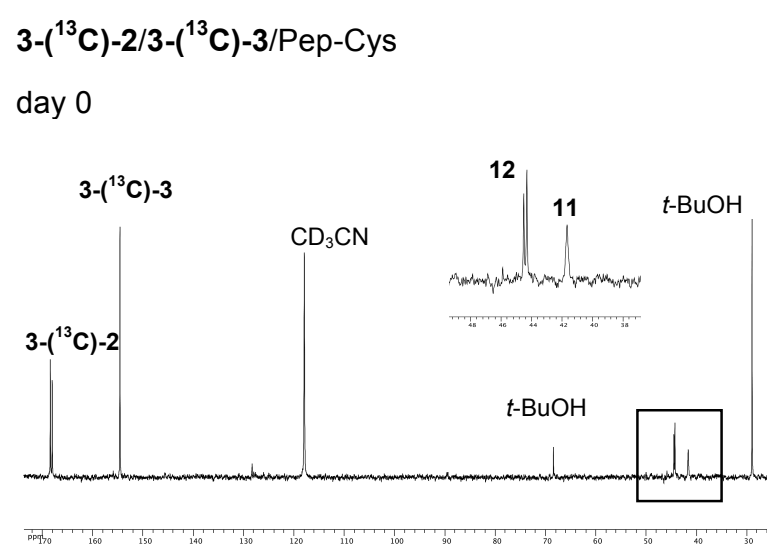

day 36
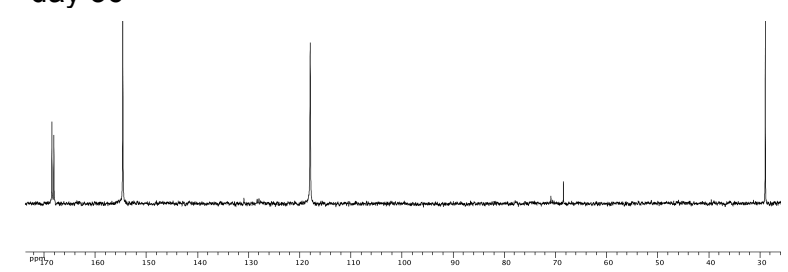

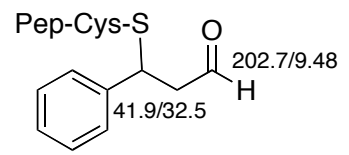

11

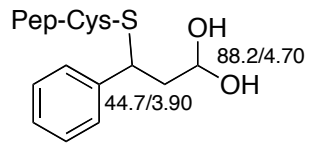

12 cinnamaldehyde with Pep-Cys:

Figure 6. Reactivity citralrepresentative 1D ${ }^{\mathrm{C}} \mathrm{C}$ NMR spectra and characteristic ${ }^{\mathrm{i}} \mathrm{C}$ and ${ }^{\mathrm{H}} \mathrm{H}$ data of adducts formed 
Figure 7

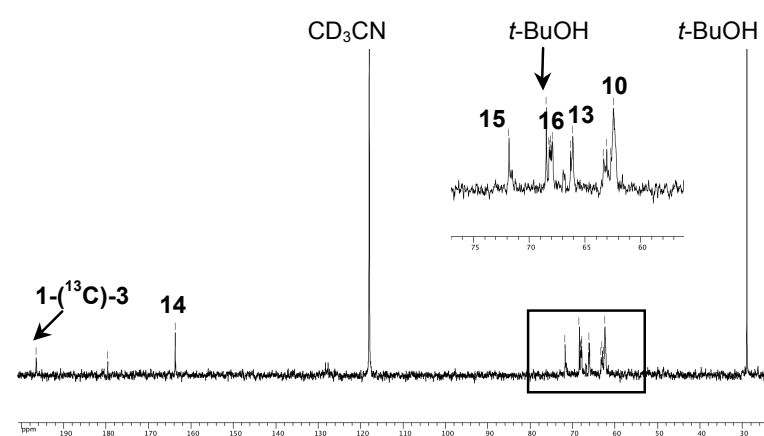

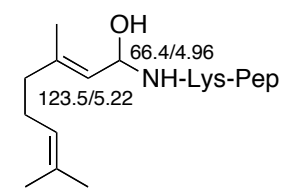

13

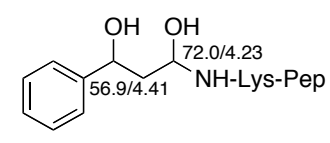

15

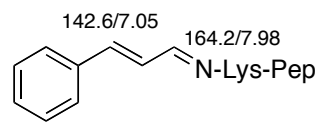

14

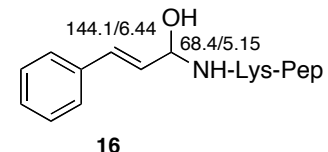

16

Figure 7. Reactivity citral-cinnamaldehyde/Pep-Lys: representative 1D $\mathrm{C}$ NMR spectrum of the reaction 1-("'C)-2/1-("C)-3/Pep-Lys, adducts formed and characteristic " $\mathrm{C}$ and $\mathrm{H}$ NMR data 


\section{Figure 8}
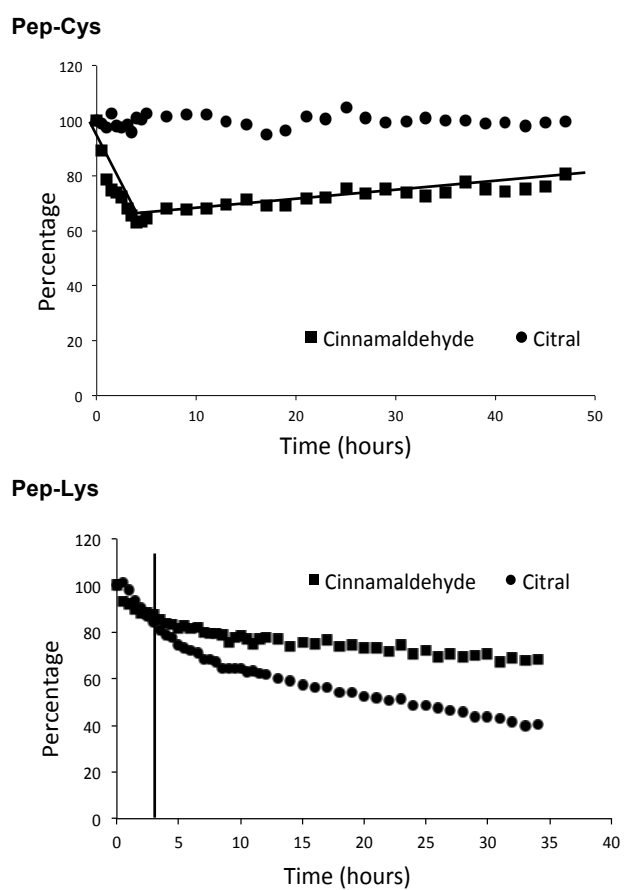

Figure 8. Evolution as a function of time of the concentration of cinnamaldehyde and citral in the mixture in the presence of Pep-Cys and Pep-Lys 